\title{
Research on the Innovation Contribution of Unmanned Convenience Stores in the Business Model of the Catering Industry
}

\author{
Xiying Zhong ${ }^{1}$ Yanxia Zhang,** \\ ${ }^{I}$ Guangzhou College of Technology and Business, Guangzhou, Guangdong 510850, China \\ *Corresponding author. Email: xmcard@126.com
}

\begin{abstract}
With the continuous penetration of mobile Internet and smart technology into people's lives, the Internet generation with high spending power and demand has become an important consumer group. The current market demand for mobile phone online ordering, ranking, and payment continues to rise. At the same time, the demand for convenience, personalization and comfort of catering consumption is also increasing. Self-service, autonomy, and intelligence will become an important development direction for catering in the future. Unmanned catering, which uses high-tech smart technology and the Internet to replace some of the employees' labor, has been questioned by many businesses in recent years, but it is still the development direction that many businesses plan to solve the traditional catering manpower, rent, food materials, energy costs, and low gross profit. Based on the value proposition and marketing perspective, the author analyzes the innovative contribution of unmanned convenience stores in the catering business model from the perspectives of unmanned convenience restaurants in meeting consumer demand, corporate product supply, and corporate profit contributions, and refines its shortcomings and difficulties and proposes Insights and enlightenment, in order to provide theoretical support and reference for the business model innovation of today's catering industry.
\end{abstract}

Keywords: Unmanned convenient restaurant, Business model, Consumer demand, Innovation contribution, Value proposition.

\section{INTRODUCTION}

Since the emergence of the Eatsa unmanned restaurant in the United States in 2015, the concept of "unmanned restaurant" has begun to enter the eyes of the world. In the following two years, unmanned stores have become a gimmick for the transformation and upgrading of various industries. With the upgrading of consumption in recent years, the rapid development of the Internet, the "lazy" economy, and the emergence of big data, unmanned supermarkets, new types of unmanned and convenient catering shops such as unmanned containers, and unmanned restaurants have sprung up accompanied by hightech, for example, Amazon Go in the United States, McDonald's Future Restaurant 2.0, unmanned

*Project: The Phased Achievements of the National University Student Innovation and Entrepreneurship Training Program One GO Portable Unmanned Restaurant in 2019, Project No.: $201913714001 \mathrm{X}$ vending machines everywhere in Japan, Alibaba unmanned restaurants and JD JOY'S smart restaurants in China, etc. According to research, the concept of unmanned people is mainly realized through high-tech smart technologies such as face recognition, WeChat Alipay scan code or swiping face to enter and exit stores and payment, automatic deduction, RFID tag identification of goods, and platform self-service ordering. As a result, the essence of unmanned convenient catering stores is a advanced strategy to replace labor with smart technology, provide more convenient services for catering consumers and reduce costs for catering companies, so as to help traditional catering companies solve the "four highs and one low" dilemma. Although unmanned convenient restaurants are trapped by high-cost technology and traditional consumption concepts, the convenience stores with the concept of "unmanned" still have great research value. 
2. RESEARCH ON THE CONTRIBUTION OF UNMANNED CONVENIENCE STORES TO INNOVATION IN THE BUSINESS MODEL OF THE CATERING INDUSTRY

\subsection{The Innovative Contribution of Unmanned and Convenient Restaurants to Meet Consumer Demand}

\subsubsection{Satisfying the Value Proposition of Customers' Sense of Science and Technology}

Science and technology are the primary productive forces, and the core of unmanned and convenient restaurants is unmanned, convenient and catering. Among them, unmannedness and convenience are manifested by the use of science and technology. From the time when consumers start to become interested in this type of store or participate in the production of store menus, they can learn store and product information from WeChat/Alipay applet/public account; At the same time, customers need to go through the store access control system before purchasing meals offline, and show the QR code on their mobile phones to enter the store. Then, in the process of choosing meals and purchasing meals, they must be monitored by the front desk, identification and tracking of dynamic and static image equipment, back-end storage of personal data, and in-depth algorithm analysis to summarize all the data of the customer's entire consumption process. The in-store equipment will provide insights into the customer's next behavior and potential needs, and a variety of high-tech and intelligent technologies will work together. This determines that the unmanned convenience store has the label of a sense of technology from the beginning of its birth.

\subsubsection{Meeting the Value Proposition of Consumer Convenience}

Science and technology brings convenience. Technological innovation is a more powerful way to achieve convenience. People's yearning for technological life is undoubtedly for the pursuit of maximum convenience. The value proposition of unmanned convenience restaurants to satisfy consumers' convenience mainly includes two aspects: The first is mainly to allow consumers to quickly choose their favorite meals and complete the settlement during the three-meal peak period, so as to realize that consumers can pass through the store "by the way", take away the food "handily", and no longer need to experience the boredom, anxiety, and urgency caused by the queues and other meals brought by traditional Chinese restaurants, which can solve the pain points of lunch and dinner, queuing for food purchase, and long queue time for consumers; The second is that the main products of unmanned convenient restaurants are meals + soups + fruit/nut nutrition packages, which not only provide consumers with healthy, green and nutritious meals, but also play a role in reducing the time cost for consumers to choose a nutritious meal combination.

\subsubsection{Meeting the Value Proposition of Consumer Channel Innovation (Diversity)}

The catering industry has a huge market potential, and mobile clients with convenient features will be the key for the catering industry to break through the traditional business model. On the one hand, on the basis of the original offline consumer demand channels and Internet consumer channels, more convenient mobile Internet consumer channels have been added, and catering companies can understand and meet the individual needs of consumers through multiple channels. At the same time, consumers can also choose consumption channels according to their own demand for convenience; on the other hand, the popularization of mobile electronic payment methods, the realization of online and offline catering $\mathrm{O} 2 \mathrm{O}$ consumption experience, and the emergence of smart restaurants have provided catering consumers with unprecedented convenience. Unmanned convenient catering stores use the promotion methods of online consumption and offline experience, combined with social marketing, and realize multichannel promotion and sales in many aspects, so that the main products of unmanned convenient catering stores can be exposed to consumers' eyes.

\subsubsection{Satisfying the Value Proposition of Consumer Liberalization}

This article discusses the value proposition of unmanned convenience restaurants to meet consumer liberalization from two aspects: the liberalization of shopping process and the liberalization of product selection. The first is that when buying food in an unmanned convenient restaurant, the entire shopping process from showing the $\mathrm{QR}$ code to the door to leaving the door without password payment is liberalized and self-service. There is no waiter to open the door to order food, no cashier to collect payment, no staff can be seen in the store, consumers 
only need to follow the instructions in the store and hold a smart phone to complete the entire meal purchase process; the second is the freedom of product choice. No one in the store means that there is no waiter to recommend meals, detailed information about the products in the store, and the degree of popularity. It is entirely up to consumers to make choices according to their own wishes. Therefore, consumers can decide for themselves whether to enter the store to consume, choose meals, and buy meals.

\subsection{The Innovative Contribution of Unmanned and Convenient Restaurants to the Supply of Enterprise Products}

\subsubsection{Using the Community to Obtain Consumer Preferences in Advance}

At present, there are two general dining methods in China, one is for consumers to take meals offline, and the other is takeaway: offline takeaways take meals and deliver meals, and consumers eat meals. The common point of the two is that consumers can choose and order online meals through APPs or websites such as phone/WeChat in advance. Unmanned convenient catering stores obtain consumer preferences in advance through WeChat official accounts, WeChat groups, QQ groups and other communities, which is equivalent to preselecting and ordering meals, realizing online meal selection and ordering, offline meal-taking and dining. In summary, compared to the previous two, unmanned convenient catering stores fully reflect consumers' self-service dining. First, the selection of meals in unmanned and convenient restaurants is not based on the menus made by the restaurant itself, but consumers decide the style of meals through community gathering and voting, and then the restaurant decides to make the set menu on their behalf; second, unmanned convenient catering stores follow the take-and-drink meal that consumers personally come to the store to take the meal and dine.

\subsubsection{Product Supply Form - Chinese Nutrition Package}

According to the survey, $87.04 \%$ of catering consumers prefer the combination of rice + vegetables + soup, and unmanned convenient catering stores design specific main product nutrition packages according to consumer needs. Survey consumers' interest in this package is divided into three indicators: will be interested, may be interested, and will not be interested. Among them, $43.83 \%$ of consumers said they would be interested, $44.44 \%$ said they might be interested, and $11.73 \%$ said they would not be interested. To sum up, the main product meal + soup + nut/fruit nutrition package designed by unmanned convenient catering stores based on consumer preferences has a good market prospect.

\subsubsection{Enhancing Consumer Experience and Gaining Additional Added Value}

The improvement of people's living standards will inevitably lead to the improvement of the quality of life, and the guarantee of the improvement of the quality of life is the quantity of resources needed for life, which directly leads to the increase of psychological pressure; incredibly, the increase in psychological stress nowadays is exposed in all aspects of life, such as transportation, work and rest, diet, work, etc. The pain points of traditional restaurants are the boredom, anxiety, and urgency brought by the long meal time and waiting for meals. If consumers are in a bad mood, the food will become tasteless or even unpalatable, which affects the user's consumption experience. Diet is the main way for people to consume life energy, and its irregularities and deficiencies will affect the foundation of human life. Unmanned and convenient restaurants help consumers to achieve an upgraded consumption experience that is quick and easy, without waiting, and avoiding unhealthy emotions such as boredom, anxiety, and urging.

\subsection{The Innovative Contribution of Unmanned and Convenient Restaurants to Enterprise Profits}

\subsubsection{Income from Selling Nutrition Package Meals}

The improvement of living standards has made people increasingly pay attention to and pursue environmentally friendly, green, and healthy lifestyles. As the most basic life activity of people, people's attention to diet cannot be ignored. As the "lazy economy" has become popular in daily life, in order to adapt to the new trend, many traditional restaurants have gradually ignored or deliberately ignored the key issue of food quality in the process of seeking "fast", which gave birth to the fast food era. However, this is not an era in which catering companies can survive in a sustained and stable manner. Currently, with the outbreak of the COVID- 
19 virus in Wuhan, green and healthy diets have become an urgent need for more and more consumers, which will derive a new type of value proposition, that is, the pursuit of fast, healthy and nutritious meals. The core meals provided by the unmanned convenient restaurant are Chinese-style nutrition packages. Nutritionists use various ingredients to provide customers with daily essential nutrients to meet consumers' needs for healthy and nutritious meals and make profits for the enterprise.

\subsubsection{Generating License Fees for User Portrait Data}

So far, the main source of profit for traditional restaurants is from the sale of meals. Although this income method has been used for many years, with the increase in labor costs, consumption upgrades, rising prices and other factors, the restaurants are generally facing a situation of difficulty in survival or on the verge of bankruptcy. Therefore, traditional restaurants are constantly pursuing reform and innovation of profit sources to meet the development requirements of the times. During this period, there were many cases of using the sharing economy to reduce the cost of food ingredients, opening online stores to reduce rent costs, and improving user consumption experience to increase profits, but these sources of income did not substantially shake the income from the sale of meals as the main source of profit in the traditional catering industry. The emergence of unmanned catering can undoubtedly change the status quo of the "four highs and one low" of the traditional catering industry. It draws more complete user portrait data and sells it to other restaurants by using high-tech intelligent technologies such as character recognition and tracking, in-depth algorithms, dynamic and static image analysis, back-end storage, front-end monitoring, and automatic deductions, which has given birth to user portrait data licensing fees for enterprise profits.

\section{CONCLUSION}

\subsection{Insufficiency and Predicament of Unmanned Convenient Catering Business Model}

\subsubsection{The Technology Is Not Mature Enough and Its Application in the Catering Industry Is Narrow}

The main body of the innovation of the unmanned convenient catering business model is the high-tech intelligent technology. It is still in the continuous research and development and trial stage in China. Among them, the application of person recognition and tracking is still limited to retail stores, logistics, vehicles, crime investigation and other fields. The dynamic and static image analysis and in-depth algorithms have passed the preliminary trials of smart retail, and further exploration is needed for mature applications in the catering industry.

\subsubsection{High Cost of Early Stage Smart Technology Equipment}

Things are precious when they are rare. The hightech intelligent technology adopted by unmanned convenient restaurants is undoubtedly expensive. The market price of unique RFID electronic tags is 0.5 yuan/piece. The huge demand will lead to high costs, as will in-depth algorithms, identification tracking, and dynamic and static image analysis. Therefore, the cost of smart technology equipment in the early stage of unmanned convenient restaurant is high.

\subsubsection{Humanized Service Is Slightly Lower than That of Traditional Restaurants}

The business model of traditional catering stores is mainly based on human resources. Affected by traditional consumption concepts, catering consumers need to rely on catering company employees to enjoy humanized services throughout the dining process. The benchmark of the unmanned convenient catering business model is unmanned. By applying high-tech intelligent technology to replace traditional catering labor, it is more convenient, fast and efficient to help catering consumers realize self-service services. Therefore, compared with traditional catering stores, the unmanned convenient catering business model is slightly lower in terms of humanized services.

\subsubsection{Unmanned, Convenient and Smart Catering Outlets Have a Poor Reputation Recently}

In the past two years, convenient and smart stores have grown on the "outflow", and they have instantly become the target of catering practitioners to follow. They have quickly spawned and become dying. They have become "pits" in various industries. It refreshes 
the death rate of the Internet concept, but the main reason for its rapid death rate is that high-tech intelligent technology is not yet mature. High-tech and intelligent technology is the general trend of the world's development, so it is still the general direction that various industries are exploring and pursuing.

\subsection{The Enlightenment of Unmanned Convenience Stores in the Business Model of the Catering Industry}

\subsubsection{Nutritional Catering Has Become a New Demand for Future Catering Consumers}

The severely developed novel coronavirus pneumonia in the world in 2020 has caused the world to pay more attention to hygiene and health. Traditional catering has been exposed by the media many times due to issues such as catering quality and hygiene, so the catering industry is bound to face the test of a new round of transformation and upgrading and business model innovation. The innovation of the main product in the business model of unmanned convenient catering stores - nutrition package will provide a feasible reference and enlightenment for catering companies.

\subsubsection{The Prospects for the Development of High-tech and Intelligent Technologies in China Are Considerable}

The high-tech intelligent technology involved in the innovation of the unmanned convenient catering business model has considerable domestic development prospects. For example, the accuracy rate of the world's top Suning face recognition technology in MegaFace reaches $96+\%$, and the experimental result on LFW reaches $99.8333+\%$. In addition, there are also Ali's "same product" identification, RFID technology, and Geling Shentong's security technology.

\subsubsection{The Application of Technology Strengthens Customers' Smart, Convenient and Self-service Consumption Experience}

The advantages of humanized experience of traditional catering companies not only bring humanized and humanized experience to catering consumers, but also bring them some bad experiences, such as boredom and anxiety caused by food purchases, as well as a sense of urgency, etc. Under the current situation of increasing competitive pressure, consumers are gradually tending to selfservice consumption experience relative to the humanized consumption experience; secondly, the "lazy" economy is advancing by leaps and bounds, and convenient and intelligent consumption experience has become the high pursuit of the new generation of consumer groups.

\section{AUTHORS' CONTRIBUTIONS}

Xiying Zhong wrote the manuscript. Yanxia Zhang contributed to revising and editing

\section{REFERENCES}

[1] Shengshihuayan, Research Report on the Problems and Countermeasures in the Development of China's Unmanned Restaurant Industry from 2019 to 2025 [R]. Shenzhen Shengshihuayan Business Management Co., Ltd., 2018. (in Chinese)

[2] Jin Yan, Dong Minhua, Investigation and Research on Hangzhou Wufangzhai Unmanned Restaurant in the New Retail Environment [J]. Modern Marketing (Information), 2019(10). (in Chinese)

[3] Chen Kexin, Analysis of the business model of the catering industry in the context of smart retail - Taking Galison Smart Food Truck as an Example [J]. Market Weekly, 2019(06). (in Chinese)

[4] Li Jing, Discussion on the Relationship Between Business Model and Corporate Performance Based on the Perspective of Business Model Innovation Classification $[\mathrm{J}]$. Journal of Commercial Economics, 2019 (11). (in Chinese)

[5] Kong Jian, Researcg on Business Model Innovation of Small Catering Based on Context - Take ZJKY Company as an Example [D]. Zhejiang Sci-Tech University, 2018 (11). (in Chinese)

[6] Su Muhui, Smart Restaurants Frequently Appear "Black Technology" Reshapes the Catering Industry? [J]. New Industrial Economy, 2019 (04). (in Chinese)

[7] Osterwalder, Alexander. Business Model Generation [M]. Mechanical Technology Press, 2011. 